\title{
Efficacy of the ethanol extracts of the leaves of some plant species on the mortality of maize weevils, Sitophilus zeamais (Curculionidae: Coleoptera) and prevention of grain damage
}

\author{
Mastewal Alehegn ${ }^{1}$, Destaw Damtie ${ }^{1, *}$, Melaku Wale $^{1}$, Yewulsew Kebede ${ }^{1}$ \\ ${ }^{1}$ Bahir Dar University, College of Science, Department of Biology
}

\begin{abstract}
Sitophilus zeamais (maize weevil) damages maize, a major cereal crop in Ethiopia. A study was conducted to determine the anti-weevil activities of ethanol extracts of leaves of Juniperus procera, Phytolacca dodecandra, Ostegia integrifolia, Sansevieria trifasciata, and Eucalyptus globulus. Extraction was done using 70\% ethanol. Two types of tests (toxicity and efficacy) were conducted using three doses, i.e., 50,75 , and $100 \mathrm{ml} / \mathrm{kg}$ of each plant. In the toxicity test, weevil mortality was measured at the $6^{\text {th }}, 12^{\text {th }}, 24^{\text {th }}, 48^{\text {th }}$, and $72^{\text {nd }}$ hours, then weekly for five weeks. For efficacy test, weevil mortality and grain damage (weight loss, percent holes, and percent germination) were assessed three months after treatment. J. procera and $P$. dodecandra were more toxic (96.6\% and $96.4 \%$ mortality rate, respectively). The 50 and $75 \mathrm{ml} / \mathrm{kg}$ doses of E. globulus, 75 and $100 \mathrm{ml} / \mathrm{kg}$ doses of J. procera, of $P$. dodecandra, and of S. trifasciata killed $100 \%$ of the weevils; in the control mortality was $23.3 \%$. Grain weight loss was high in the control $(7.8 \%)$ followed by grains treated by $75 \mathrm{ml} / \mathrm{kg}$ extracts of $O$. integrifolia $(5.9 \%)$. Percentage holes was high in the control $(70 \%)$ followed by $75 \mathrm{ml} / \mathrm{kg}$ extracts of $O$. integrifolia $(26.7 \%)$. Germination was high in grains treated with 50 and $75 \mathrm{ml} / \mathrm{kg}$ doses of J. procera, E. globulus, S. trifasciata, and P. dodecandra in descending order. The 75 and 100 $\mathrm{ml} / \mathrm{kg}$ extracts of J. procera, E. globulus, S. trifasciata, and P. dodecandra were good candidates in the control of maize weevils with limitations of allelopathy in the $100 \mathrm{ml} / \mathrm{kg}$.
\end{abstract}

Keywords: Juniperus procera, Maize weevil, Ostegia integrifolia, Phytolacca dodecandra, Sansevieria trifasciata, Sitophilus zeamais.

DOI: https://dx.doi.org/10.4314/ejst.v13i2.5

\section{INTRODUCTION}

Zea mays (maize or corn) is one of the vital cereal grains widely cultivated and consumed in Africa. Despite its extensive utilization as human and

\footnotetext{
${ }^{*}$ Correspondence: zegades96@gmail.com

(C)This is an Open Access article distributed under the terms of the Creative Commons Attribution License (http://creativecommons.org/licenses/CC BY4.0)
} 
animal feed, its productivity is hindered by pest infestation. Annually, more than $\$ 100$ billion is lost due to maize grain damage by pests such as weevils (Edelduok et al., 2015). Maize infestation by the larvae and adults of weevil begins in the field and most damage occurs in stores (Khaliq et al., 2014). Damage of maize grains by weevils results in food shortage, increased poverty, low nutritional value, increased malnutrition, reduced grain weight and market values, and reduced germination (Suleiman et al., 2015). Natural pesticides (botanicals), directly extracted from plants, have the potential to replace the otherwise unfriendly synthetic pesticides (Qwarse et al., 2016) and serve as alternatives to synthetic pesticides (Hikal et al., 2017). In Ethiopia, farmers traditionally use non-chemical pest control methods (Gebeyaw Tilahun, 2015). They use local herbs like Datura stramonium, Carissa schimperi, Croton macrostachys, Phytolacca dodecandra, Tagetes minuta, Weinia longiflora, and Allium sativum to reduce storage pest infestation by S. zeamais (Gebeyaw Tilahun, 2015; Hikal et al., 2017).

The mechanism of action of plant extracts varies with the type of plant. Extracts can act as repellents (Kareru et al., 2013), as suppressants of reproductive behavior of the pest insects and reducing their fecundity and fertility (Nasiru et al., 2016) or interfering with their life cycle (Kareru et al., 2013). The insecticidal activities of plants are due to their secondary metabolites such as alkaloids, phenolics, tannins, and terpenoids (Perera et al., 2017). Previous reports showed different extracts of $P$. dodecandra (Phytolaccaceae) (Qwarse et al., 2016), S. trifasciata (Ruscaceae) (Potenza et al., 2005), J. procera (Karunamoorthi et al., 2014), and E. globulus (Myrtaceae) (Mandudzi and Edziwa, 2016) have some insecticidal properties against $S$. zeamais. The present study, thus, was aimed at determining the efficacy of $P$. dodecandra, E. globulus, $O$. integrifolia, $J$. procera, and S. trifasciata leaf extracts on weevil mortality, grain loss due to weevil damage, and seed germination of maize.

\section{MATERIALS AND METHODS}

\section{Description of the study area}

The study was carried out in Bahir Dar University, Biomedical Research Laboratory, Bahir Dar, Ethiopia. The city of Bahir Dar is located in northwestern Ethiopia at an altitude of $1800 \mathrm{~m}$ above sea level, at $11^{\circ} 38^{\prime}$ North latitude and $37^{\circ} 15^{\prime}$ East longitude. It enjoys a mean annual rainfall is $1419 \mathrm{~mm}$ and temperature of $19.6^{\circ} \mathrm{C}$ (Mitiku Muluye et al., 2017). 
Study Design

Weevils were subjected to three levels of each plant extract $(50 \mathrm{~mL} / \mathrm{kg}, 75$ $\mathrm{mL} / \mathrm{kg}$, and $100 \mathrm{~mL} / \mathrm{kg}$ ) in a completely randomized design (CRD) in the laboratory and each extract level was replicated three times.

\section{Acquisition of grains to be used for rearing test organisms}

Some $50 \mathrm{~kg}$ of clean maize grain (not treated with chemicals) was purchased from the Bahir Dar market. The grains were disinfected in the oven at $40{ }^{\circ} \mathrm{C}$ for $4 \mathrm{~h}$. The disinfected grains were kept in the laboratory in tightly closed plastic beakers before use. Dirt from the maize was removed through winnowing.

\section{Collection and rearing of the maize weevils}

Adult weevils were collected from farmers and traders' stores in Bahir Dar and Merawi (35 km southwest from Bahir Dar). The weevils were mixed and released into maize grains reserved for rearing the initial weevil stock. First, they were mass-reared in separate containers (tin cans covered with muslin cloth at the top). They were introduced into the maize seeds and the container was kept at room temperature for reproduction to take place. Unsexed adult weevils were introduced into jars containing uninfested maize grains. The jars were covered with a piece of muslin cloth held in place by a rubber band to prevent the weevils from escaping. The emerging (new generation) weevils ( 0 to 1 -week old) were used for a series of experiments that followed (Edelduok et al., 2015).

\section{Collection, preparation, and extraction of plant materials}

Arial parts of plants were collected between October and December 2017 from different places in the Amhara region, Ethiopia. E. globulus was collected from the Debre Markos area, $O$. integrifolia from Yejube, $P$. dodecandra from Abay Gorge, near the Ethiopian Grand Renaissance Dam, $J$. procera from Dangila, and S. trifasciata from Wollo, near Sirinka. These plants were chosen based on recommendations from local people (informants). The collected plant parts were air-dried under a shade at room temperature in the laboratory, pulverized into powders, and then active ingredients extracted using 70\% ethanol $(1: 5 \mathrm{gm} / \mathrm{ml}$ ratio $)$ and placed on a shaker for 21 days (Mandal et al., 1999). After 21 days, the extracts were strained using sterile cotton and filter paper. The filtrates then were stored in sterile brown reagent bottles and placed in a refrigerator at $4{ }^{\circ} \mathrm{C}$ until used for experimentation. 


\section{Phytochemical analysis}

The chemical constituents of the extracts were qualitatively screened for the presence of the phytochemical groups/classes according to the method described before (Jaradat et al., 2015) and the standard technique (Sheela, 2013). The active constituents of the extracts were qualitatively confirmed for the presence of alkaloids, terpenoids, tannins, saponins, phenolics, flavonoids and glycosides. Test for chemical constituents was done as described by Jaradat et al. (2015) (phenols), Zohra et al. (2012) (tannins), Ayoola et al. (2008) (flavonoids), Diouf et al. (2016) (saponins), Karthishwaran et al., (2010) (terpenoids), and Zohra et al. (2012) and Pandey and Tripathi (2014) (alkaloids).

\section{Toxicity test against maize weevils}

The contact method was used to test the toxicity of the extracts against maize weevil using three different concentrations $(50,75$, and $100 \mathrm{ml} / \mathrm{kg}$ grain). Twenty grams of maize grains were put into each of 93 plastic vials. Extracts were added and the mixtures were shaken for five minutes to ensure uniform coating of grains. Ten adult $S$. zeamais were introduced into each vial and then covered with the muslin cloth. In the blank control, twenty grams of maize and ten adult insects were introduced. Three replicates were made for each treatment. The weevil mortality was assessed at the $6^{\text {th }}, 12^{\text {th }}, 24^{\text {th }}, 48^{\text {th }}$, $72^{\text {nd }}$ hours, and weekly up to five weeks after the insects were introduced. The insects were considered dead when they didn't respond to gentle probing with a sharp pin at the abdomen (Ouko et al., 2017). The number of dead and live insects was recorded and percentage mortality was calculated.

\section{Testing the efficacy of the plant extracts on weevil mortality, seed damage, and seed germination}

A random sample of $200 \mathrm{~g}$ of maize seeds was taken and kept in each of the 93 plastic beakers. The maize samples were treated with 50, 75, and 100 $\mathrm{ml} / \mathrm{kg}$ of the $70 \%$ leaf ethanol extracts of the $P$. dodecandra, S. trifasciata, $J$. procera, and E. globulus. Each dose was applied in triplicates. Three of the grain samples were not treated by any plant extract and served as controls. Twenty adult weevils were introduced into the treated and control grains and the beakers were covered with a muslin cloth to facilitate proper aeration and to prevent the escape of weevils. Three months after treatment, the weevil mortality and grain damage (weight loss, percent holes, and percent germination) were measured.

Mortality test: Percent weevil mortality was calculated using the formula (Muzemu et al., 2013) 


$$
\text { Parent weevil mortality }=\frac{N D}{T N} \times 100 \%
$$

Where $N D=$ number of dead weevils and $T N=$ total number of weevils initially introduced into the flask.

Grain damage test: Grain weight loss due to infestation with S. zeamais was calculated using the formula used by Melaku Wale and Tesfaye Mengie (2017).

$$
\text { Weight loss } \%=\frac{(I D W-F D W)}{I D W} \times 100 \%
$$

Where IDW $=$ Initial dry weight and FDW $=$ Final dry weight.

Besides, the extent of weevil damage was assessed by counting the number of seeds with holes. Grains with exit-holes were counted and the percentage holes $(\mathrm{PH})$ of the weevils to the grains were calculated using the formula used by Melaku Wale and Tesfaye Mengie (2017).

$$
P H=\frac{T N G H}{T N G} \times 100 \%,
$$

Where PH stands for percentage holes, TNGH for the total number of treated grains with holes, TNG for the total number of grains.

Germination test: Surface sterilized maize seeds were treated with all plant extracts at different concentrations $(10,15$, and $20 \mathrm{ml})$. After three months, the germination test was carried out in a completely randomized design by taking 20 seeds from the five treatments of each plant product. A random sample of 20 seeds was taken from each treatment set and placed each in a Petri dish (11 cm diameter) lined with cotton. The Petri dishes were covered to prevent loss of moisture and contamination and placed in an environmental chamber. The temperature was maintained at $23{ }^{\circ} \mathrm{C}$ and the dishes exposed to constant light conditions. After one week the number of seeds germinated was counted and recorded. Germination percentage was calculated using the formula given below (Muzemu et al., 2013).

$$
\text { Germination percentage } \%=\frac{G 1}{G 2} \times 100
$$

Where $\mathrm{G} 1=$ total germinated grain, G2 = total grain in Petri dish.

\section{Data analysis}

Weevil mortality, number of holes per seed, grain loss, and rate of seed germination against the leaves extracts of the test plants were subjected to Analysis of Variance (ANOVA) procedure using the SAS statistical program (SAS, 2003). Means were compared using the Tukey HSD test at $\alpha=0.05$. 


\section{RESULTS}

\section{Phytochemical constituents of the plant extracts}

Qualitative phytochemical analysis of secondary metabolites showed that $P$. dodecandra contained alkaloids, terpenoids, tannins, saponins, flavonoids, and phenols. J. procera contained all the above except saponins, E. globulus contained all the above except flavonoids, and $O$. integrifolia and $S$. trifasciata have all the above except terpenoids (Appendix 1).

\section{Toxicity test against maize weevils}

After six and $12 \mathrm{~h}$ exposure, J. procera extracts showed significantly higher mortality than the other plant extracts (Figure 1b). As exposure time increased, the effectiveness of J. procera, P. dodecandra, S. trifasciata, and $E$. globulus increased. The result of $O$. integrifolia (and the control) was low compared to the other four plant extracts. Based on potency, the six treatments could be grouped into two, i.e., J. procera, $P$. dodecandra, $S$. trifasciata, and E. globulus (in decreasing order of effectiveness) in one group and $O$. integrifolia and the control in another. The $100 \mathrm{ml} / \mathrm{kg}$ dose of the $70 \%$ ethanol extract of all plants was most effective. The trend of weevil mortality due to the $70 \%$ ethanol extract at $100 \mathrm{ml} / \mathrm{kg}$ doses was $100 \%(J$. procera, E. globulus, and S. trifasciata); close to $100 \%$ ( $P$. dodecandra); and $60 \%$ (O. integrifolia) (Figures 1a-e).

\section{Weevil mortality and measures of grain damage after extract treatment}

Three months after treatment by the $70 \%$ extract, the percentages of weevil mortality due to the 50,75 , and $100 \mathrm{ml} / \mathrm{kg}$ extracts of E. globulus, J. procera, $P$. dodecandra, and $S$. trifasciata were significantly higher than that of the 50 and $75 \mathrm{ml} / \mathrm{kg}$ extracts of $O$. integrifolia and the control. But mortality due to all doses of all the extracts was significantly higher than that of the control (Table 1). Grain damage was measured indirectly by measuring weight loss, percent holes in grains, and germination three months after extract application. Weight loss in the control grains $(7.8 \%)$ was significantly higher than grains treated with plant extracts except for the lower doses of O. integrifolia (5.9\%). Similarly, the percentage of holes in the control group $(70 \%)$ was significantly higher than grains treated by all the test doses of the extracts. In contrast, significantly low germination was observed in grains treated with $100 \mathrm{ml} / \mathrm{kg}$ of $P$. dodecandra $(3.3 \%) ; 100 \mathrm{ml} / \mathrm{kg}$ of $J$. procera (5\%); control (13.3\%); 50, 70, $100 \mathrm{mg} / \mathrm{kg}$ of O. integrifolia $(15 \%$, $15 \%$, and $16.7 \%$ respectively) and the maximum significant germination 
Ethiop. J. Sci. \& Technol. 13(2): 147-160, June 2020

was observed in grains treated by the $50 \mathrm{ml} / \mathrm{kg} \mathrm{J}$. procera $(60 \%), 75 \mathrm{ml} / \mathrm{kg}$ $J$. procera $(58.3 \%)$, and $50 \mathrm{ml} / \mathrm{kg}$ E. globulus $(56.7 \%)$.

\section{P. dodecandra}

a)
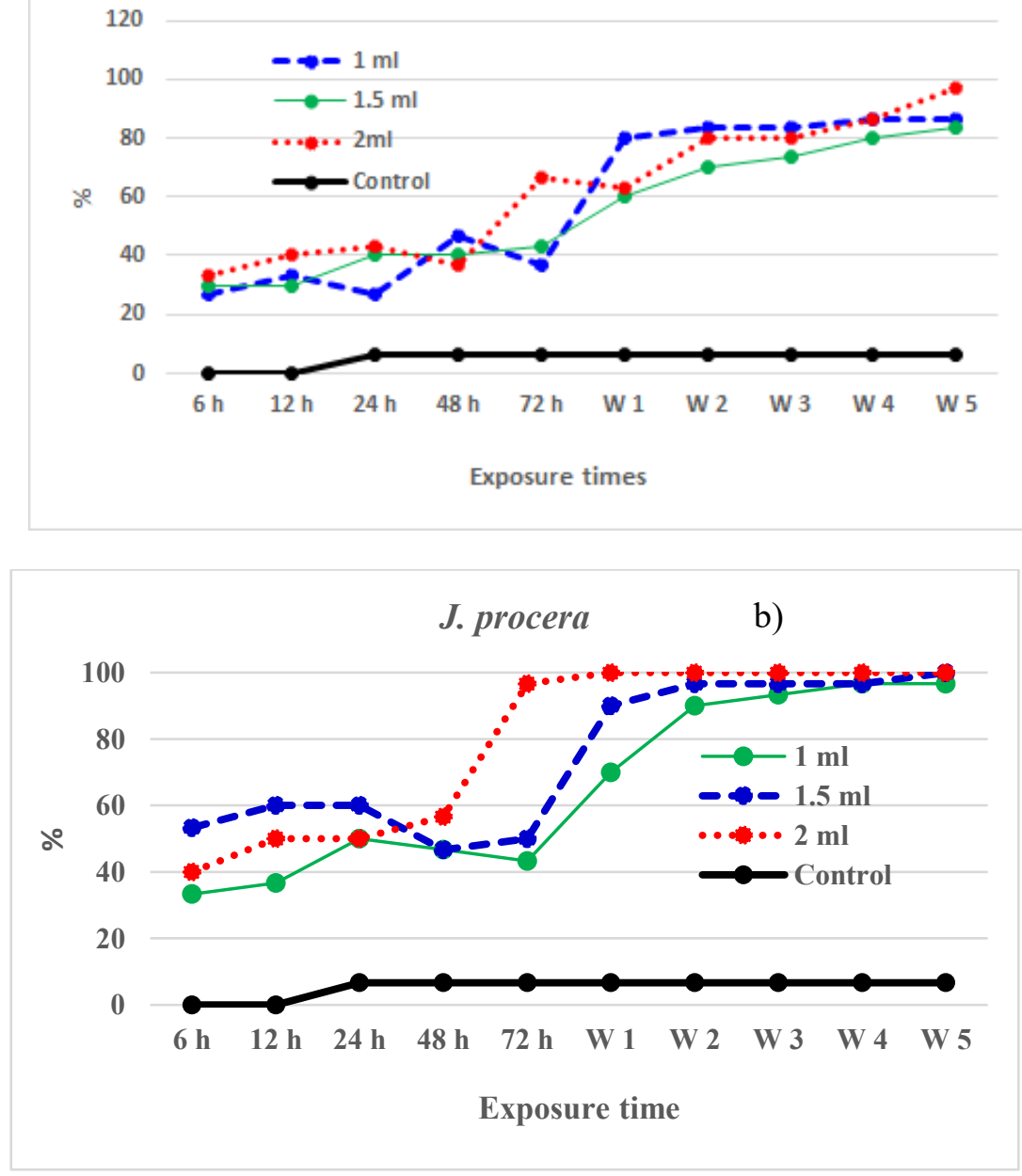


\section{O. integrifolia}

c)

100

$80 \longrightarrow-1 \mathrm{ml} \quad \longrightarrow \quad-1.5 \mathrm{ml}$

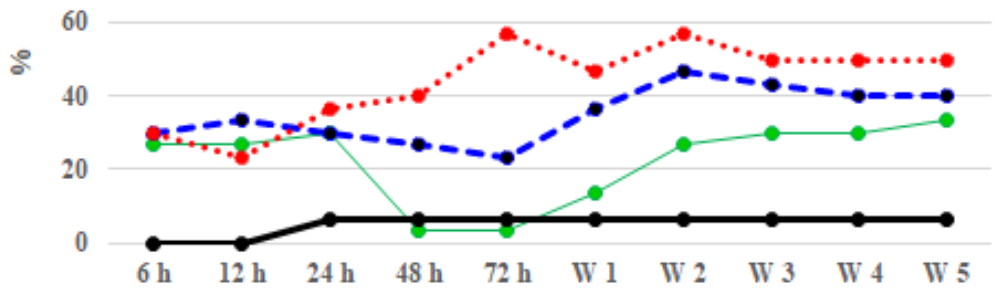

Exposure time

\section{E. globulus}

d)

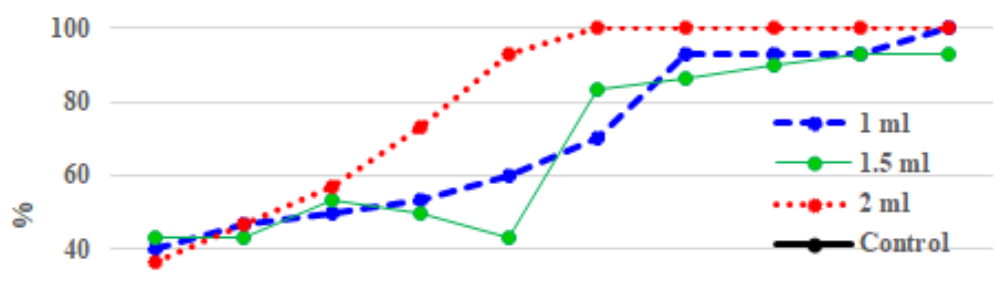

20

0

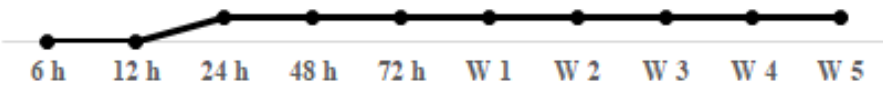

Exposure time 


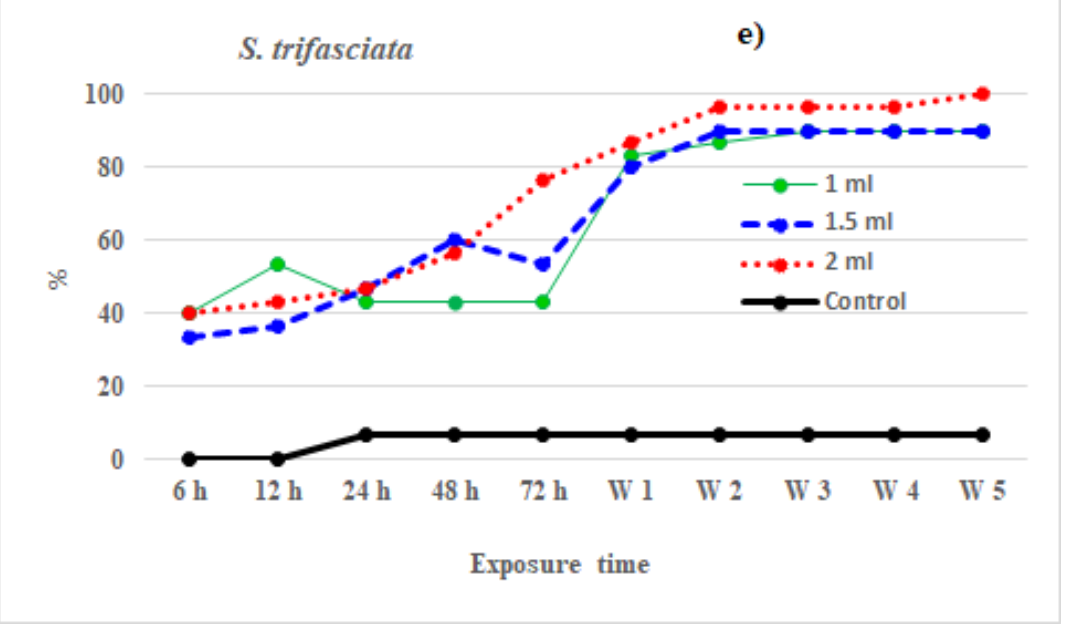

Figure 1a-e. Effect of the different doses of the plant extracts against maize weevil. (Note: $\mathrm{h}=$ hour; $\mathrm{W}=$ week)

\section{DISCUSSION}

In the current study, leaf extracts of the five plant species had alkaloids, tannins, and phenols. Similar findings were reported before (Anbu et al., 2009; Teponno et al., 2016). In a previous study, preliminary phytochemical screening of the leaf extracts of S. trifasciata had alkaloids, flavonoids, saponins, glycosides, terpenoids, tannins, proteins, and carbohydrates (Anbu et al., 2009). In contrast, Dagnew Bitew (2015) failed to find tannins on extracts of $J$. procera, a condition that might happen as a result of differences in the method of extraction or the species lacks this metabolite.

Terpenoids were detected in the ethanolic extract of leaves and roots of $P$. dodecandra, E. globulus, J. procera (Qwarse et al., 2016). The presence of terpenoids revealed that the plants can act mainly as antifeedant, growth disruptors, and toxicants towards insects (Adeniyi et al., 2010). But the absence of these phytocompounds in the extracts of $S$. trifasciata, and $O$. integrifolia may be the cause of marked reduction of their insecticidal properties. Saponins were found in all the ethanolic extracts of the leaves of $P$. dodecandra, E. globulus, O. integrifolia, and S. trifasciata but not in J. procera. In the present study, flavonoids were detected in the extracts of $P$. dodecandra, O. integrifolia, J. procera, and S. trifasciata but not in the extracts of E. globulus which may be responsible for their insecticidal properties (Adeniyi et al., 2010). 
The initial bio-potential of plant extracts was mainly based on concentration and exposure period (Figure 1a-e). All plants tested were not effective during the first $48 \mathrm{hrs}$. This may be because botanicals do not have immediate knockdown effects as do synthetic pesticides, but the poisoned insects will stop feeding almost immediately (https://hgic.clemson.edu/factsheet/less-toxic-insecticides/). However, after 72 hours, the rate of mortality increased sharply. Maximum weevil mortality was recorded for the leaf extracts of $J$. procera, $P$. dodecandra, $S$. trifasciata, and E. globulus, but was less for O. integrifolia. This may be due to the presence of terpenoids in the former plant extracts. Terpenoids in plants have antifeedant and growth disruptor properties towards insects (Adeniyi et al., 2010).

$J$. procera and $P$. dodecandra had the highest mortality rate within five weeks of exposure at all concentrations. The effectiveness of J. procera against insects has also been done by other researchers. For example, it was highly effective against mosquito larvae (An. arabiensis) (Karunamoorthi et al., 2014). P. dodecandra was the second-best performer next to J. procera against maize weevils. E. globulus was also effective against snails, mosquito larvae, houseflies, and rodent pesticides such as rats (Qwarse et al., 2016).

The next effective plant species was $S$. trifasciata. Similarly, it was effective against $S$. zeamais in previous work (Potenza et al., 2005) followed by $E$. globulus. According to Mandudzi and Edziwa (2016), E. globulus had a repellent effect on the olfactory and gustatory system of $S$. zeamais. The order of mortality of the weevils was: J. procera $>P$. dodecandra $>S$. trifasciata $>E$. globulus $>O$. integrifolia. However, there was some difference in mortality between the doses of each plant extract. The $2 \mathrm{ml}$ of each extract was the most effective of all. Ojebode et al. (2016) reported similar results in which $2 \%$ extract resulted in complete mortality. Toxicity has increased with increasing dose and time of exposure. O. integrifolia had little effect on weevil mortality when compared to the other plant extracts. The untreated grains had the lowest weevil mortality as compared with the extract-treated grains.

There was an increase in mortality with an increase in extract dose from 75 and $100 \mathrm{ml} / \mathrm{kg}$ grain. In another study, the effectiveness of $P$. dodecandra was also justified, whereby its application at a rate of $150 \mathrm{mg} / \mathrm{ml}$ concentration killed $98 \%$ of $S$. zeamais (Qwarse et al., 2016). The presence of holes indicates that weevils have fed on grains. As a whole, $70 \%$ of the untreated and less than $1 \%$ of the $J$. procera, $P$. dodecandra, S. trifasciata, and E. globulus treated maize grains had holes at the end of the $3^{\text {rd }}$ month. However, in grains treated with $O$. integrifolia extract, the percentage of 
holes was $25.0 \%, 26.7 \%$, and $6.7 \%$ for the doses of 50,75 , and $100 \mathrm{ml} / \mathrm{kg}$ grain, respectively. This implies that the extracts of $J$. procera, $P$. dodecandra, $S$. trifasciata, and E. globulus had a protective role against weevil infestation.

Grain weight loss in seeds treated with $J$. procera, $P$. dodecandra, $S$. trifasciata, and E. globulus extracts was significantly lower than grains treated with $O$. integrifolia and the control. Grain damage or weight loss recorded in the treated maize seeds with the four plant extracts was generally low. This result agrees with previous reports (Melaku Wale and Tesfaye Mengie, 2017). The development of weevils in the untreated grain was not hindered and they had a high rate of feeding (Cosmas et al., 2012).

The percentage of seed germination in grains treated with $O$. integrifolia extract was significantly lower than seeds treated with E. globulus (50 and $75 \mathrm{ml} / \mathrm{kg}$ ), J. procera $(50$ and $75 \mathrm{ml} / \mathrm{kg}$ ), P. dodecandra $(50$ and $75 \mathrm{ml} / \mathrm{kg}$ ), and $S$. trifasciata $(50,75$, and $100 \mathrm{ml} / \mathrm{kg})$ and was comparable to the control group. However, germination of seeds treated by the highest dose (100 $\mathrm{ml} / \mathrm{kg}$ ) of E. globulus, J. procera, and $P$. dodecandra was very low indicating the allelopathic effects of these extracts at the highest doses. Generally, germination of the seeds treated with the plant extracts was relatively low because of their allelopathic secondary metabolites like phenols. For example, Eucalyptus contains phenols (active allelochemicals) (Ziaebrahim et al., 2007).

\section{CONCLUSION}

The evidence gathered from the current study confirmed that the leaf extracts of J. procera, P. dodecandra, S. trifasciata, and E. globulus protected weevil attack of maize grains and reduced grain damage. Therefore, these plants could be used as candidate anti-weevils in botanical preparations. In contrast, compared to the other four plant species, $O$. integrifolia did not protect seeds from the weevil attack, and worse, it reduced seed germination.

\section{ACKNOWLEDGMENTS}

Bahir Dar University, Biotechnology Research Institute is acknowledged for the fund granted to undertake this research work. 
Table 1. Effect of different plants extracts against maize weevils (mortality and damage).

\begin{tabular}{|c|c|c|c|c|}
\hline \multirow{2}{*}{$\begin{array}{l}\text { Dose } \\
(\mathrm{ml} / \mathrm{kg})\end{array}$} & \multirow{2}{*}{$\begin{array}{c}\text { Weevil } \\
\text { mortality (\%) }\end{array}$} & \multicolumn{3}{|c|}{ Measures of grain damage (\%) } \\
\hline & & Weight loss & Holes & Germination \\
\hline \multicolumn{5}{|c|}{ Control } \\
\hline 0 & $23.3 \pm 5.24^{\mathrm{f}}$ & \multicolumn{2}{|l|}{ E. globulus } & $13.3 \pm 2.7^{\mathrm{e}-\mathrm{g}}$ \\
\hline 50 & $100.0 \pm 5.24^{\mathrm{a}}$ & $1.5 \pm 0.4^{\mathrm{g}}$ & $0.0 \pm 3.3^{\mathrm{e}}$ & $56.7 \pm 2.7^{\mathrm{ab}}$ \\
\hline 75 & $100.0 \pm 5.24^{\mathrm{a}}$ & $1.5 \pm 0.4^{\mathrm{g}}$ & $0.0 \pm 3.3^{\mathrm{e}}$ & $45.0 \pm 2.7^{\mathrm{bc}}$ \\
\hline 100 & $98.3 \pm 5.24^{\mathrm{a}}$ & $1.9 \pm 0.4^{\mathrm{g}}$ & $0.0 \pm 3.3^{\mathrm{e}}$ & $25.0 \pm 2.7^{\mathrm{de}}$ \\
\hline 50 & $98.3 \pm 5.24^{\mathrm{a}}$ & $\begin{array}{l}\text { J. procera } \\
1.8 \pm 0.4^{\mathrm{g}}\end{array}$ & $1.7 \pm 3.3^{\mathrm{e}}$ & $60.0 \pm 2.7^{\mathrm{ab}}$ \\
\hline 75 & $100.0 \pm 5.24^{\mathrm{a}}$ & $1.0 \pm 0.4^{\mathrm{g}}$ & $0.0 \pm 3.3^{\mathrm{e}}$ & $58.3 \pm 2.7^{\mathrm{ab}}$ \\
\hline 100 & $100.0 \pm 5.24^{\mathrm{a}}$ & $1.3 \pm 0.4^{\mathrm{g}}$ & $0.0 \pm 3.3^{\mathrm{e}}$ & $5.0 \pm 2.7^{\mathrm{fg}}$ \\
\hline \multicolumn{5}{|c|}{ O. integrifolia } \\
\hline 50 & $66.7 \pm 5.24^{\mathrm{b}-\mathrm{d}}$ & $4.3 \pm 0.4^{\mathrm{b}-\mathrm{e}}$ & $25.0 \pm 3.3^{\mathrm{b}-\mathrm{d}}$ & $15.0 \pm 2.7^{\mathrm{e}-\mathrm{g}}$ \\
\hline 75 & $45.0 \pm 5.24 \mathrm{~d}-\mathrm{f}$ & $5.9 \pm 0.4^{\mathrm{ab}}$ & $26.7 \pm 3.3^{b c}$ & $15.0 \pm 2.7^{\mathrm{e}-\mathrm{g}}$ \\
\hline 100 & $80.0 \pm 5.24^{\mathrm{a}-\mathrm{c}}$ & $4.3 \pm 0.4^{\mathrm{b}-\mathrm{e}}$ & $6.7 \pm 3.3^{\text {de }}$ & $16.7 \pm 2.7^{\mathrm{e}^{-\mathrm{g}}}$ \\
\hline \multicolumn{5}{|c|}{ P. dodecandra } \\
\hline 50 & $96.7 \pm 5.24^{\mathrm{a}}$ & $1.6 \pm 0.4^{\mathrm{g}}$ & $0.0 \pm 3.3^{\mathrm{e}}$ & $50.0 \pm 2.7^{\mathrm{a}^{-\mathrm{c}}}$ \\
\hline 75 & $100.0 \pm 5.24^{\mathrm{a}}$ & $1.3 \pm 0.4^{\mathrm{g}}$ & $0.0 \pm 3.3^{\mathrm{e}}$ & $46.7 \pm 2.7^{b c}$ \\
\hline 100 & $100.0 \pm 5.24^{\mathrm{a}}$ & $1.7 \pm 0.4^{\mathrm{g}}$ & $0.0 \pm 3.3^{\mathrm{e}}$ & $3.3 \pm 2.7^{\mathrm{g}}$ \\
\hline \multicolumn{5}{|c|}{ S. trifasciata } \\
\hline 50 & $93.3 \pm 5.24 \mathrm{ab}$ & $2.1 \pm 0.4^{\mathrm{e}-\mathrm{g}}$ & $0.0 \pm 3.3^{\mathrm{e}}$ & $51.7 \pm 2.7^{\mathrm{a}^{-\mathrm{c}}}$ \\
\hline 75 & $100.0 \pm 5.24^{\mathrm{a}}$ & $1.6 \pm 0.4^{\mathrm{g}}$ & $0.0 \pm 3.3^{\mathrm{e}}$ & $50.0 \pm 2.7^{\mathrm{a}-\mathrm{c}}$ \\
\hline 100 & $100.0 \pm 5.24^{\mathrm{a}}$ & $1.6 \pm 0.4^{\mathrm{g}}$ & $0.0 \pm 3.3^{\mathrm{e}}$ & $26.7 \pm 2.7^{\mathrm{de}}$ \\
\hline
\end{tabular}

Note: Similar letters in the column indicate not significant difference $(P=0.05)$.

\section{REFERENCES}

Adeniyi, S.A., Orjiekwe, C.L., Ehiagbonare, J.E., and Arimah, B.D. (2010). Preliminary phytochemical analysis and insecticidal activity of ethanolic extracts of four tropical plants (Vernonia amygdalina, Sida acuta, Ocimum gratissimum, and Telfaria occidentalis) against bean weevils (Acanthscelides obtectus). International Journal of the Physical Sciences 5(6):753-762.

Anbu, J.S.J., Jayaraj, P., Varatharajan, R., Thomas, J., Jisha, J and Muthappan, M. (2009). Analgesic and antipyretic effects of Sansevieria trifasciata leaves. African Journal of Traditional, Complementary, and Alternative Medicines 6(4): 529-533.

Ayoola, G., Coker, H.A.B, Adesegun, S.A., Adepoju, A.A., Obaweya, K., Ezennia, E.C., Atangbayila, T.O. (2008). Phytochemical screening and antioxidant activities of some selected medicinal plants used for malaria therapy in Southwestern Nigeria. Tropical Journal of Pharmaceutical Research 7(3):1019-1024.

Cosmas, P., Christopher, G., Charles, K., Friday, K., Ronald, M., Belta, M.Z. (2012). Tagetes minuta formulation effect Sitophilus zeamais (Weevils) control in stored maize grain. International Journal of Plant Research 2(3): 65-68.

Dagnew Bitew. (2015). Assessment of the inhibitory activity of resin from Juniperus procera against the mycelium of Pyrofomes demidoffi. Journal of Plant Pathology and Microbiology 6:291. 
Diouf, E.H.G., Diop, M., Sene, A. and Samb, A. (2016). Phytochemical screening and insecticidal activity of three extracts of Tapinanthus bangwensis (Engl. \& Krause) on Sitophilus zeamais (Maize Weevil). Open Access Library Journal 3(8):1-10.

Edelduok, E. GLOBULUS., Akpabio, E.E., Eyo, J.E. and Ekpe E.N. (2015). Evaluation of the insecticidal activities of cotyledon powder of melon, Citrullus vulgaris Schrad against the maize weevil, Sitophilus zeamais Motsch. Journal of Biopesticides and Environment 1:50-57.

Gebeyaw Tilahun (2015). Evaluating grain protectant efficacy of some botanicals against maize weevil, Sitophilus zeamais. World Journal of Agricultural Research 3(2): 66-69.

Hikal, W.M, Rowida, S and Hussein, A.H. (2017). Botanical insecticide as simple extractives for pest control. Cogent Biology 3: 14-23.

https://hgic.clemson.edu/factsheet/less-toxic-insecticides/. Less Toxic Insecticides. (Accessed on 29 Feb 2020).

Jaradat, N., Hussen, F and Ali, A.A. (2015). Preliminary phytochemical screening quantitative estimation of total flavonoids, total phenols and antioxidant activity of Ephedra alata Decne. Journal of Materials and Environmental Science 6(6): 1771-1778.

Kareru, P., Rotich, Z.K and Maina, E.W. (2013). Use of botanicals and safer insecticides designed in controlling insects: The African case. In Tech, Winchester, UK.

Karthishwaran, K., Mirunalini, S.D., Hamodharan, G, Krishnaveni, G and Arulmozhi, V. (2010). Phytochemical investigation of methanolic extract of the leaves of Pergularia daemia. Journal of Biological Sciences 10(3): 242-246.

Karunamoorthi, K., Askual, Girmay and Samuel Fekadu. (2014). Larvicidal efficacy of Ethiopian ethnomedicinal plant Juniperus procera essential oil against Afrotropical malaria vector Anopheles arabiensis (Diptera: Culicidae). Asian Pacific Journal of Tropical Biomedicine 4(1): 99-106.

Khaliq, A., Nawaz, A., Ahmad., M.H., Sagheer, M. (2014). Assessment of insecticidal potential of medicinal plant extracts for control of maize weevil (Motschulsky), (Coleoptera: Curculionidae). Basic Research Journal of Agricultural Science and Review 3(11):100-104.

Mandal, S.C., Pal (Dutta), S., Maity, T.K., Pal, M., and Saha, B.P. (1999). Preparation and Evaluation of tincture of Azadirachta indica A. Juss. Leaves. Ancient Science of Life 19(12):69-73.

Mandudzi, E. and Edziwa, X. (2016). Eucalyptus leaf powder is effective in maize weevil control. International Journal of Agriculture and Forestry 6(2): 93-98

Melaku Wale and Tesfaye Mengie. (2017). Effect of organic products (Lupine oil and Areki) against maize weevil (Sitophilus zeamais) on stored maize grains (Zea mays). International Journal of Entomology Research 2(2):79-84.

Muzemu, S., Chitamba, J and Goto, S. (2013). Screening of stored maize (Zea mays L.) varieties grain for tolerance against maize weevil, Sitophilus zeamais (Motsch.). International Journal of Plant Research 3(3): 17-22.

Nasiru, A. M., Sambo, S., Sulaiman, B., Yalli, A.A., Liman, B., Nahantsi, M.S and Aliyu, L.S. (2016). Insecticidal activity of commonly used plants for the control of stored maize weevil (Sitophilus zeamais) In Sokoto State. International Journal of Innovative Food, Nutrition \& Sustainable Agriculture 4(4):36-3.

Ojebode, M.E., Olaiya, C.O., Adegbite, A.E, Karigidi, K.O., Ale, T.O. (2016). Efficacy of some plant extracts as storage protectants against Callosobruchus maculatus. Journal of Biotechnology and Biomaterials 6(1):2-4.

Ouko, R.O., Koech, S.C, Arika, W.M., Osano, K.O., Ogola, P.E., Oduor, R.O and Ngugi, M.P. (2017). Bioefficacy of organic extracts of A. sativum against S. zeamais (Coleoptera; Dryophthoridae). Biological Systems 6(1):2-7.

Pandey, A and Tripathi, S. (2014). Concept of standardization, extraction and pre phytochemical screening strategies for herbal drug. Journal of Pharmacognosy and Phytochemistry 2(5): 115-119.

Perera, A.G.W.U., Karunaratne, M.M.S.C and Chinthaka, S.D.M. (2017). Biological activity and secondary metabolite profile of Ruta graveolens leaves against maize weevil infestations. Journal of Entomology and Zoology Studies 5(2): 233-241.

Potenza, M.R., Junior, J., Alves, N. (2005). Evaluation of contact activities of plant extracts against Sitophilus zeamais Motschulsky (Coleoptera: Curculionidae). Alternative Methods to 
Chemical Control (9th International Working Conference on Stored Product Protection) 811815.

Qwarse, M., Mihale, M.J., Henry, L., Sempombe, J and Veronica, M. (2016). Pesticidal activity of Phytolacca dodecandra extracts against Sitophilus zeamais (Motschulsky) (Curculionidae) and Tribolium castaneum (Tenebrionidae) storage pests in maize. Journal of Food Security 4(6): 147-155.

Sheela, J.A.H. (2013). Qualitative analysis of secondary metabolites of the plant Clematis gouriana. International Journal of Innovative Research in Science, Engineering and Technology 2(6):23-56.

Suleiman, R., Rosentrater, K.A., Bern, C.J. (2015). Evaluation of maize weevils Sitophilus zeamais Motschulsky infestation on seven varieties of maize. Journal of Stored Products Research 64(2): 97-102.

Teponno, R.B., Tanaka, C., Jie, B., Tapondjou, L.A and Miyamoto, T. (2016). Trifasciatosides A-J, steroidal saponins from Sansevieria trifasciata. Chemical and Pharmaceutical Bulletin 64(9):1347-1355.

Ziaebrahimi, L. Khavari-Nejad, R.A., Fahimi, H. and T. Nejadsatari (2007). Effects of aqueous Eucalyptus extracts on seed germination, seedling growth and activities of peroxidase and polyphenoloxidase in three wheat cultivar seedlings (Triticum aestivum L.). Pakistan Journal of Biological Sciences 10(19): 3415-3419.

Zohra, S.F., Meriem, B., Samira, S., Muneer, M.S.A. (2012). Phytochemical screening and identification of some compounds from Mallow. Journal of Natural Products and Plant Resources 2(4):512-516.

Appendix 1. Phytochemical composition of the plant extracts.

\begin{tabular}{lllllll}
\hline Plant extract & \multicolumn{7}{c}{ Secondary metabolites } \\
\cline { 2 - 7 } & Alkaloids & Terpenoids & Tannins & Saponins & Flavonoids & Phenols \\
\hline J. procera & + & + & + & - & + & + \\
P. dodecandra & + & + & + & + & + & + \\
E. globulus & + & + & + & + & - & + \\
O. integrifolia & + & - & + & + & + & + \\
S. trifasciata & + & - & + & + & + & + \\
\hline
\end{tabular}

Note: The qualitative results are expressed as $(+)$ for the presence and (-) for the absence of phytochemicals. 